\title{
Analisis Kesalahan Siswa dalam Menyelesaikan Penjumlahan Bilangan Bulat Berdasarkan Teori Kastolan
}

\author{
Rahma Aulia Sari ${ }^{1}$, Wulida Arina Najwa ${ }^{2}$ \\ ${ }^{1}$ SDN Belitung 1 Banjarmasin, Jl. Pembangunan 1 No.12, Kota Banjarmasin, Kalimantan Barat. \\ ${ }^{2}$ STKIP Al Hikmah Surabaya, Jl. Kebonsari Elveka V, Kota Surabaya, Jawa Timur. \\ Corresponding author's : ${ }^{1}$ rahmaauliasari3117@gmail.com, ${ }^{2}$ najwaarina@gmail.com

\section{Analysis of Student Errors in Completing Spotting of Round Numbers Based on Castolan Theory}

\begin{tabular}{l} 
Kata Kunci \\
\hline Analisis kesalahan, \\
teori kastolan, bilangan \\
bulat.
\end{tabular}

Keywords:

Error analysis, castor theory, integers.

\begin{abstract}
Abstrak
Belajar matematika diperlukan kemampuan berfikir logis dan kritis, tidak hanya belajar menghitung. Oleh karena itu, membelajarkan konsep menjadi sangat penting. Banyak siswa yang memiliki konsep tidak benar, tidak lengkap dan sebagainya. Akibatnya, terjadi kesalahan-kesalahan ketika siswa mengerjakan soal matematika sederhana. Penelitian ini dilakukan dengan tujuan untuk mengetahui jenis kesalahan siswa berdasarkan tahapan kastolan. Tahapan kastolan digunakan meliputi kesalahan konsep, kesalahan prosedur dan kesalahan teknik. Penelitian ini merupakan penelitian kualitatif. Subjek penelitian adalah siswa kelas VI SDN Belitung Selatan 1 Banjarmasin. Prosedur pemilihan subjek menggunakan purposive sampling. Teknik pengumpulan data yang digunakan adalah tes dan wawancara. Tes berbentuk soal uraian. Teknik analisis data yang digunakan adalah reduksi data, penyajian data dan penarikan kesimpulan. Berdasarkan data hasil penelitian dapat disimpulkan bahwa siswa melakukan kesalahan konsep, kesalahan prosedur dan kesalahan teknik. Masing-masing siswa melakukan kesalahan tersebut dengan indikator yang berbeda-beda.
\end{abstract}

\section{Abstract:}

Learning mathematics requires the ability to think logically and critically, not only learning to count. Therefore, teaching concepts is very important. Many students have incorrect, incomplete concepts and so on. As a result, mistakes occur when students do simple mathematics. This research was conducted with the aim of knowing the errors in the castor stage. The stages of castor are used including concept errors, procedure errors and technic errors. This research is a qualitative research. The research subjects were students of grade VI SDN Belitung Selatan 1 Banjarmasin. The procedure for selecting subjects used purposive sampling. The data techniques used were tests and interviews. The test is in the form of description questions. The data analysis technique used was data reduction, data presentation and data collection. Based on the research data, it can reveal that students made misconceptions, procedural errors and technical errors. Each student made these mistakes with different indicators.

\section{PENDAHULUAN}

Belajar matematika tidak bisa dilakukan dengan menghafal, melainkan harus dipahami dan di ikuti dengan pengembangan kemampuan berfikir kritis, logis cermat, kreatif. Pembelajaran matematika merupakan suatu proses atau kegiatan guru dalam mengajarkan matematika kepada peserta didik yang di dalamnya terkandung upaya guru untuk menciptakan iklim dan pelayanan terhadapan kemampuan, potensi, minat, bakat, dan kebutuhan peserta didik yang beragam agar terjadi interaksi optimal antara guru dengan peserta didik serta peserta didik dengan peserta didik dalam mempelajari matematika. 
Kondisi di lapangan menunjukkan bahwa tidak banyak siswa yang sudah belajar matematika dengan tepat. Akibatnya, dalam belajar maupun mengerjakan soal matematika siswa tersebut banyak melakukan kesalahan. Banyak faktor yang menyebabkan siswa melakukan kesalahan dalam menyelesaikan soal matematika. (Lai, 2012) menyebutkan bahwa beberap faktor siswa melakukan kesalahan dalam menyelesaikan soal matematika diantaranya kurangnya pengetahuan terhadap materi dan lemahnya perhatian siswa terhadap materi. Selain kedua faktor tersebut, materi yang sulit termasuk dalam salah satu penyebab siswa melakukan kesalahan (Nikmah, 2019). Operasi hitung bilangan bulat menjadi materi dasar yang seharusnya dikuasai oleh siswa sekolah dasar. Apabila ia masih sering melakukan kesalahan pada materi ini maka akan berpengaruh terhadap materi yang lain. Seperti yang dituliskan (Dyson, 2015) bahwa operasi hitung merupakan materi dasar dan menjadi pondasi untuk materi matematika yang lain.

Salah satu teori yang dapat digunakan untuk menganalisis kesalahan siswa dalam menyelesaikan soal matematika adalah Kastolan. (Kastolan, 1992) menyebutkan bahwa kesalahan dalam matematika dibagi menjadi 3 jenis, yaitu kesalahan konseptual, kesalahan prosedural dan kesalahan teknik. Kesalahan konseptual merupakan kesalahan yang dilakukan siswa dalam menafsir istilah, sifat, fakta, konsep dan prinsip. Kesalahan prosedural merupakan kesalahan dalam menyusun symbol, langkah peraturan yang hierarkis dan sistematis dalam menjawab suatu masalah. Kesalahan teknik yang dilakukan seperti kesalahan dalam penulisan variabel dan kesalahan memahami soal.

Penelitian terdahulu terkait analisis kesalahan siswa dalam menyelesaikan soal matematika telah dilakukan. Penelitian yang dilakukan oleh (Rahmawati \& Permata, 2018) menemukan hampir seluruh siswa melakukan kesalahan matematis. Kemudian kesalahan tersebut di analisis menggunakan analisis kesalahan Newman yang menunjukkan 23,33\% siswa melakukan kesalahan membaca, 81,67\% melakukan kesalahan memahami, 30\% melakukan kesalahan transformasi, 56\% melakukan kesalahan proses dan 66,67\% melakukan kesalahan penulisan jawaban akhir. Berbeda dengan penelitian (Rofi'ah, 2019) yang menggunakan analisis kesalahan Polya, menunjukkan bahwa 20,65\% siswa melakukan kesalahan dalam memahami, 26,18\% siswa melakukan kesalahan dalam merencanakan, 26,39\% melakukan kesalahan dalam menyelesaikan soal dan $26,74 \%$ siswa melakukan kesalahan dalam memerika hasil pekerjaannya. Oleh karena itu, peneliti bermaksud menganalisis kesalahan siswa dalam menyelesaikan soal penjumlahan bilangan bulat menggunakan teori Kastolan.

\section{METODE PENELITIAN}

Penelitian ini menggunakan pendekatan kualitatif deskriptif. Penelitian kualitatif deskriptif yaitu mendeskripsikan analisis kesalahan siswa menggunakan teori Kastolan dalam menyelesaikan soal operasi hitung bilangan bulat. Subjek penelitian sebanyak 6 orang yang merupakan siswa kelas VI SDN Belitung Selatan 1 Banjarmasin tahun 2019/2020. Pemilihan subjek berdasarkan teknik sampling, yaitu mengambil salah satu siswa yang melakukan kesalahan konseptual, prosedural dan teknik ketika diberikan soal operasi hitung bilangan bulat. Setelah siswa diberikan soal, peneliti menganalisis hasil pekerjaan sesuai dengan indikator analisis kesalahan Kastolan yag diadaptasi dari (Khanifah \& Nusantara, 2011) dan (Widyantari, 2016).

Tabel 1. Indikator Analisis Kesalahan kastolan

\begin{tabular}{|c|c|c|}
\hline No & Jenis Kesalahan & Indikator \\
\hline \multirow[t]{4}{*}{1} & Kesalahan konseptual & $\begin{array}{l}\text { Siswa tidak dapat memilih rumus yang benar atau siswa } \\
\text { lupa terhadap rumus yang harus digunakan. }\end{array}$ \\
\hline & & $\begin{array}{l}\text { Siswa benar dalam memilih rumus namun tidak dapat } \\
\text { menerapkan rumus tersebut dengan benar. }\end{array}$ \\
\hline & & $\begin{array}{l}\text { Siswa tidak dapat menentukan rumus untuk menjawab } \\
\text { suatu masalah. }\end{array}$ \\
\hline & & $\begin{array}{l}\text { Siswa menggunaan rumus, teorema, atau definisi yang } \\
\text { tidak sesuai dengan kondisi prasyarat berlakunya rumus. }\end{array}$ \\
\hline 2 & Kesalahan prosedural & $\begin{array}{l}\text { Siswa melakukan langkah penyelesaian soal yang tidak } \\
\text { sesuai. }\end{array}$ \\
\hline
\end{tabular}

Siswa tidak dapat menyelesaikan soal sampai pada bentuk paling sederhana sehingga perlu dilakukan langkahlangkah lanjutan. 
Siswa tidak runtut dalam melakukan langkah-langkah perhitungan.

Siswa tidak mampu memanipulasi langkah-langkah untuk menjawab suatu masalah.

$3 \quad$ Kesalahan teknik

Siswa melakukan kesalahan dalam menghitung nilai dari suatu operasi hitung.

Siswa melakukan kesalahan dalam memindahkan nilai konstanta atau variabel dari satu langkah ke langkah berikutnya.

Setelah menganalisis masing-masing pekerjaan siswa, peneliti selanjutnya mendeskripsikan kesalahan subjek dalam menyelesaikan masalah penjumlahan bilangan bulat. Langkah terakhir adalah menuliskan laporan penelitian.

\section{HASIL DAN PEMBAHASAN}

Penelitian ini dilakukan dengan memberikan tes berupa soal materi operasi hitung bilangan bulat kepada siswa kelas VI SDN Belitung Selatan 1 Banjarmasin. Hasil tes tersebut dianalisis untuk melihat jenis kesalahan yang dilakukan siswa dan menentukan subjek penelitian. Dari hasil analisis ditemukan beberapa kesalahan yang dilakukan berdasarkan kategori Kastolan. Selanjutnya dipilih 6 siswa yang jenis kesalahannya mewakili tiga jenis kesalahan, yaitu kesalahan konseptual, kesalahan prosedur dan kesalahan teknik. Berdasarkan hasil data yang diperoleh, berikut ini adalah jenis-jenis kesalahan dan faktor-faktor penyebab kesalahan siswa dalam menyelesaikan soal operasi hitung bilangan bulat.

\section{Kesalahan Konspetual}

Berdasarkan indikator yang sudah diuraikan sebelumnya, kesalahan konseptual terjadi karena siswa tidak dapat menentukan rumus yang benar dalam mengerjakan soal yang diberikan atau lupa terhadap rumus yang harus digunakan. Selain itu, kesalahan konseptual juga dapat terjadi ketika siswa dapat memilih rumus yang benar namun tidak dapat menggunakan rumus tersebut. Kesalahan tersebut dilakukan oleh subjek B-03 dan B-17 seperti pada gambar berikut:

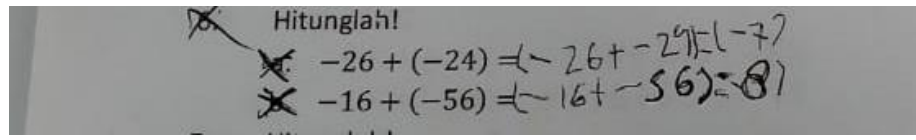

Gambar 1 Kesalahan Konseptual Siswa B-03

Pada gambar 1 point (a) dapat dilihat bahwa siswa dapat menentukan rumus yang digunakan, namun tidak dapat menyelesaikan soal tersebut dengan benar. la tahu bahwa bilangan negatif jika dijumlahkan dengan bilangan negatif akan menghasilkan bilangan negatif juga tetapi ia tidak memahami cara penghitungannya. Hal ini mengakibatkan, hasil akhir jawaban siswa salah. Sedangkan pada nomor 1 point (b), siswa B-03 mengulang kesalahan yang sama seperti pada nomor 1 point (a).

Pada gambar 2 dapat dilihat bahwa subjek B-17 juga melakukan kesalahan konseptual tetapi dengan indikator yang berbeda dengan subjek B-03. Pada gambar 2 point (a) Subjek B17 tidak memahami makna penjumlahan bilangan negatif dengan positif. Oleh karena itu, ia mengeluarkan tanda negatif kemudian mengurangkan bilangan yang besar dengan bilangan yang lebih kecil. Hal ini menyebabkan B-17 menghasilkan jawaban akhir yang tidak tepat. Kesalahan ini juga dilakukan subjek B-17 pada gambar 2 point (b).

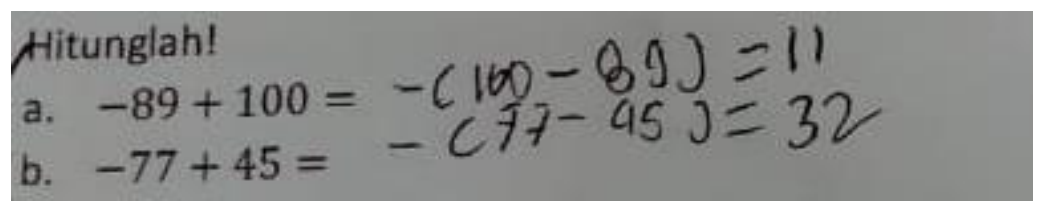

Gambar 2 Kesalahan Konseptual Siswa B-17

Berdasarkan hasil analisis tes yang diberikan pada gambar 1 dan gambar 2 dapat disimpulkan bahwa kesalahan yang dilakukan siswa disebabkan karena (a) siswa tidak memahami maksud soal, (b) siswa salah menggunakan rumus, (c) siswa tidak dapat menentukan rumus. Kesalahan konseptual yang dilakukan oleh siswa sebanding dengan penelitian (Natsir, 2016) menyatakan faktor penyebab kesalahan yang dilakukan siswa antara lain belum memahami konsep, belum dapat menerapkan konsep, dan salah menentukan rumus. Selain faktor internal tersebut, (Slameto, 2015) dan (Suryasubrata, 2004) juga mengungkapkan adanya 
faktor eksternal yang berasal dari luar individu seperti kondisi kesehatan dan lingkungan ketika mengerjakan.

\section{Kesalahan Prosedural}

Kesalahan prosedural terjadi ketika siswa menyelesaikan soal namun dengan langkah yang tidak sesuai. Selain itu, kesalahan ini juga dapat terjadi ketika siswa tidak dapat menyelesaikan soal hingga bentuk paling sederhana atau siswa tidak runtut dan tidak mampu memanipulasi langkah-langkah penyelesaikan suatu masalah. Subjek B-12 dan B-29 melakukan kesalahan procedural seperti pada gambar berikut.

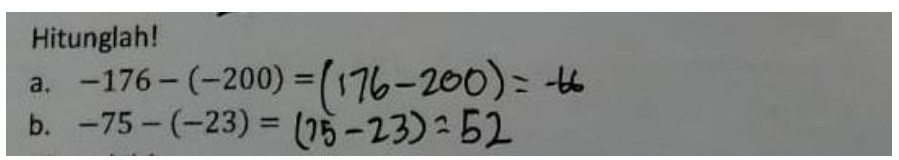

Gambar 3 Kesalahan Prosedural Siswa B-12

Pada gambar 3 point (a) dan (b), subjek B-12 menghilangkan tanda negatif pada soal sehingga menghasilkan jawaban akhir yang tidak tepat. Berdasarkan hasil wawancara, subjek B-12 menghilangkan tanda negatif pada soal karena kedua bilangan merupakan bilangan negatif. Seharusnya, jika tanda pengurangan bertemu dengan tanda negatif akan mengubah tanda menjadi positif dan tanda negatif hilang.

Pada gambar 4 point (a) dan (b) kesalahan yang dilakukan subjek B-29 hampir sama dengan yang dilakukan subjek B-12. la juga menghilangkan tanda negatif yang ada pada bilangan pertama. Tentu saja ini akan membuat jawaban akhir menjadi tidak tepat.

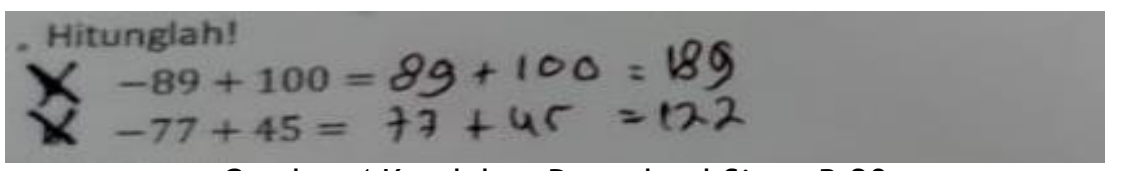

Gambar 4 Kesalahan Prosedural Siswa B-29

Berdasarkan hasil analisis tes yang diberikan pada gambar 3 dan gambar 4 dapat disimpulkan bahwa kesalahan yang dilakukan siswa disebabkan karena (a) tidak mampu melakukan prosedur dengan baik, (b) salah dalam melakukan proses pengerjaan, (c) ketidakmampuan siswa dalam memanipulasi langkah-langkah. Kesalahan prosedur dalam melakukan operasi bilangan bulat pada guru dapat menjadi sebuah ketidakjelasan yang menyebabkan ambiguitas dalam penyelesaian (Knill, 2014).

\section{Kesalahan Teknik}

Kesalahan teknik terjadi ketika siswa melakukan kesalahan dalam menghitung nilai dari operasi hitung. Kesalahan ini juga dapat terjadi ketika siswa melakukan kesalahan dalam memindahkan nilai konstanta atau variabel dari langkah-langkah pengerjaan. Subjek B-21 dan B-09 melakukan kesalahan teknik karena tidak menuliskan prosedur pengerjaan dan menuliskan jawaban akhir yang tidak tepat juga. Contoh kesalahan teknik dapat dilihat dari gambar berikut.

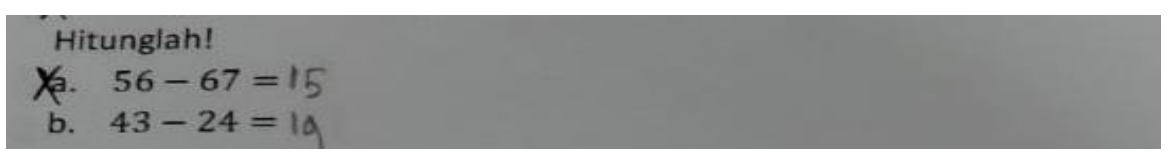

Gambar 5 Kesalahan Teknik Siswa B-21

Pada gambar 5 point (a) dapat dilihat subjek B-21 melakukan kesalahan teknik. Subjek melakukan kesalahan dalam menghitung nilai dari operasi hitung. Hal ini mengakibatkan siswa salah dalam hasil akhir Subjek tidak memahami bahwa bilangan yang dikurangkan dengan bilangan yang lebih besar akan menghasilkan bilangan negatif.

Sejalan dengan kesalahan subjek B-21, Pada gambar 6 dapat dilihat bahwa subjek B-09 melakukan kesalahan teknik pada soal bagian a dan b. Siswa melakukan kesalahan dalam menghitung nilai dari operasi hitung tersebut. Hal ini mengakibatkan siswa salah dalam menentukan hasil akhir soal tersebut.

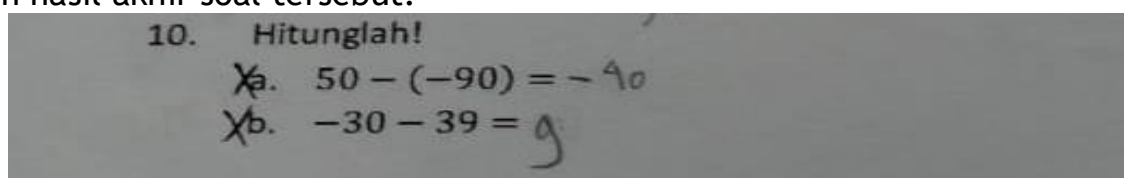

Gambar 6 Kesalahan Teknik Siswa B-09 
Berdasarkan hasil analisis tes yang diberikan pada gambar 3 dan gambar 4 dapat disimpulkan bahwa kesalahan yang dilakukan siswa disebabkan karena (a) kesalahan dalam menghitung nilai, (b) miskonsepsi terkait bilangan. Menurut penelitian (Widyaningrum, A., 2016) kesalahan tersebut disebabkan karena adanya kesalahan interpretasi soal, terlalu tergesa-gesa, dan tidak teliti dalam mengerjakan soal .

\section{KESIMPULAN}

Terdapat tiga kesalahan yang dilakukan oleh subjek dalam menyelesaikan soal matematika, yaitu kesalahan konseptual, kesalahan prosedur dan kesalahan teknik. Kesalahan tersebut dilakukan subjek dengan indikator yang berbeda-beda. Kesalahan konseptual terjadi karena ada subjek yang tidak mengerti rumus untuk menyelesaikannya, ada subjek yang mengerti rumus yang digunakan tetapi tidak dapat menerapkan rumus tersebut sehingga menghasilkan jawaban yang tidak tepat. Kesalahan prosedur terjadi karena subjek menggunakan langkah-langkah yang tidak sesuai untuk menyelesaikan soal. Kemudian kesalahan teknik terjadi karena subjek melakukan kesalahan dalam menghitung sehingga mengakibatkan jawaban akhir tidak tepat.

Saran untuk penelitian lebih lanjut terkait analisis kesalahan siswa menggunakan tahapan kastolan adalah pemberian scaffolding yang relevan dengan kesalahan yang dilakukan oleh subjek. Pemberian scaffolding sangat bermanfaat untuk subjek agar tidak melakukan kesalahan yang sama lagi. Selain itu, pemberian scaffolding juga dapat memperbaiki konsep yang dimiliki oleh subjek.

\section{DAFTAR PUSTAKA}

Dyson, N., Jordan, N. C., Beliakoff, A., \& Hassinger-Das, B. (2015). A kindergarten numbersense intervention with contrasting practice conditions for low-achieving children. Journal for Research in Mathematics Education, 46(3), 331-370. https://doi.org/10.5951/jresematheduc.46.3.0331

Kastolan. (1992). Identifikasi jenis-jenis kesalahan menyelesaikan soal-soal matematika yang dilakukan siswa kelas 2 Program A1 SMA Negeri Sekotamadya. In IKIP Malang.

Khanifah, N. ., \& Nusantara, T. (2011). Analisis Kesalahan Penyelesaian Soal Prosedural Bentuk Pangkat Bulat dan Scaffoldingnya. Jurnal Universitas Negeri Malang, 1-14.

Knill, O. (2014). Ambiguous PEMDA. Http://Www.Math.Havard.Edu.

Lai, C.-F. (2012). Error Analysis In Mathematics C.

Natsir, N., Tandiayuk, M. B., \& Karniman, T. S. (2016). Profil kesalahan konseptual dan Prosedural siswa dalam menyelesaikan soal cerita himpunan di kelas VII SMP 1 Siniu. Jurnal Elektronik Pendidikan Matematika Tadulako, 3(4), 440-453.

Nikmah, I. L., Juandi, D., \& Prabawanto, S. (2019). Students' difficulties on solving mathematical problem based on ESD objectives. Journal of Physics: Conference Series, 1157(3), 6-12. https://doi.org/10.1088/1742-6596/1157/3/032116

Rahmawati, D., \& Permata, L. D. (2018). Analisis Kesalahan Siswa Dalam Menyelesaikan Soal Cerita Program Linear Dengan Prosedur Newman. Jurnal Elektronik Pembelajaran Matematika, 5(2), 173-185.

Rofi'ah, N., Ansori, H., \& Mawaddah, S. (2019). Analisis Kesalahan Siswa Dalam Menyelesaikan Soal Cerita Matematika Berdasarkan Langkah Penyelesaian Polya. EDU-MAT: Jurnal Pendidikan Matematika, 7(2), 120. https://doi.org/10.20527/edumat.v7i2.7379

Slameto. (2015). Belajar dan Faktor-faktor yang mempengaruhi. In Rineka Cipta.

Suryasubrata. (n.d.). Psikologi pendidikan. In Rajawali Press.

Widyaningrum, A., Z. (2016). Analisis Kesulitan Siswa dalam Mengerjakan Soal Cerita Matematika Materi Aritmatika Sosial Ditinjau dari gaya Belajar Siswa Kelas VII SMP Negeri 5 Metro Tahun Pelajaran 2015/2016. Iqra', 1(2), 165-189.

Widyantari, F. (2016). Analisis Kesalahan Siswa Berdasarkan Tahapan Kastolan Dalam Menyelesaikan Soal Cerita Matematika Materi Lingkaran Kelas VIII SMP Negeri 1 Salatiga. 